\title{
Role of interleukin-6 on RANKL-RANK/osteoprotegerin system in hypothyroid ovariectomized mice
}

\author{
Janusz Mysliwiec ${ }^{1}$, Robert Zbucki ${ }^{3}$, Agnieszka Nikolajuk ${ }^{1}$, Piotr Mysliwiec ${ }^{3}$, \\ Andrzej Taranta ${ }^{2}$, Karol Kaminski ${ }^{4}$, Zofia Bondyra ${ }^{5}$, Jacek Dadan ${ }^{2}$, Maria Gorska ${ }^{1}$, \\ Maria M. Winnicka ${ }^{2}$
}

${ }^{1}$ Department of Endocrinology, Diabetology and Internal Diseases, ${ }^{2}$ Department of General and Experimental Pathology, ${ }^{3} 1^{\text {st }}$ Department of General and Endocrine Surgery, ${ }^{4}$ Department of Cardiology, ${ }^{5}$ Department of Radiology, Medical University of Bialystok, Bialystok, Poland

\begin{abstract}
Postmenopausal women frequently develop hypothyroidism. Estrogen depletion is accompanied by an increase of IL-6, accelerating bone turnover. The influence of hypothyroidism on bone metabolism in postmenopausal women is poorly understood. The aim of the study was an attempt to clarify the role of interleukin-6 on RANKL-RANK/osteoprotegerin system in hypothyroid ovariectomized mice. The study was performed on 56, 12-13 weeks old, female mice: C57BL/6J (wild-type; WT) and C57BL/6J IL6-/-Kopf (IL-6 knock-out; IL6KO). The mice were randomly divided into 8 groups with 7 mice in each one: 1/ WT controls, 2/ IL6KO controls, 3/ WT hypothyroid mice, 4/ IL6KO hypothyroid mice, 5/ WT ovariectomized, 6/ IL6KO ovariectomized, 7/ WT ovariectomized hypothyroid mice and 8/ IL6KO ovariectomized hypothyroid mice. Experimental model of menopause was produced by bilateral ovariectomy carried out in 8-9 weeks old mice. Experimental model of hypothyroidism was induced by propylthiouracyl administration in driking water. The serum levels of TRACP 5b, osteocalcin, OPG and RANKL were determined by ELISA.Serum RANKL concentrations were elevated significantly in all groups of ovariectomized mice as compared to respective controls, but in a minor degree in IL6KO hypothyroid mice as compared to wild-type animals. Moreover sRANKL values were significantly lower in IL6KO as compared to WT controls and IL6KO PTU injected mice. Osteoprotegerin serum levels were decreased in all IL-6 deficient mice and in a highest degree in sham-operated hypothyroid mice. To sum up, the results of the present study suggest that estrogens deficit is a strong stimulus for RANKL-RANK/OPG pathway that breaks an inhibitory influence of hypothyroidism even in IL-6 deficient mice.
\end{abstract}

Key words: sRANKL, OPG, IL-6, hypothyroidism, bone turnover, IL-6 knock-out mice

\section{Introduction}

It has been estimated that approximately $5 \%$ of all postmenopausal women develop hypothyroidism, mainly due to autoimmune thyroiditis [1]. Progressive estrogens deficit leads to bone mass loss, reduced skeletal strength and increased susceptibility to fractures. Estrogen depletion after menopause is accompanied by an increase in the production of several osteotropic cytokines, such as IL-6, IL-10 and Tumor

Correspondence: J. Mysliwiec, Dept .of Endocrinology,

Diabetology and Internal Diseases, Medical University

of Bialystok, Sklodowskiej-Curie Str. 24A, 15-276 Bialystok,

Poland; tel.: (+4885) 7468239, fax.: (+4885) 7447611,

e-mail: janusz.mysliwiec@umwb.edu.pl
Necrosis Factor (TNF) [2,3]. IL-6 is a pleiotropic cytokine secreted by osteoblasts, osteoclasts and stromal cells that regulates bone remodeling by promoting differentiation of osteoclasts- cells responsible for bone resorption [4]. However in conditions of active bone metabolism IL-6 may also stimulate osteoblast generation [5]. In ovariectomized mice IL-6 was shown to play a key role in bone turnover acceleration and selective inhibitor of IL-6 was documented to effectively suppress bone mass reduction [6,7]. The influence of hypothyroidism on bone metabolism in women in postmenopausal age is poorly understood.

IL-6 may exert its inhibitory effect on bone formation directly through gp130-STAT $1 / 3$ signaling or indirectly by influencing balance between osteoprotegerin (OPG) and receptor activator of nuclear factor 
$\kappa \mathrm{B}$ (RANK) and its ligand (RANKL) $[5,8]$. The influence of IL-6 on RANK-RANKL/OPG system was suggested to be powerful mechanism leading to increased bone mass loss [9]. Our experimental data suggest important influence of IL-6 on bone turnover in thyrotoxicosis and minor role of this cytokine in bone metabolism in hypothyroid state $[10,11]$. Data on IL-6 involvement in RANK-RANKL/OPG balance in conditions coexisting with estrogen deficit (connected with accelerated bone turnover) and hypothyroidism (causing a slowdown of bone metabolism) are lacking.

The aim of the present study was an attempt to clarify the role of interleukin-6 on RANKL-RANK/osteoprotegerin system in hypothyroid ovariectomized mice.

\section{Material and methods}

Experimental animals. The study was performed on 56, 12-13 weeks old, female mice: C57BL/6J (wild-type; WT) and C57BL/6J IL6--/Kopf (IL-6 knock-out; IL6KO). All animals had free access to standard granulated diet and drinking water. The animals were housed in plastic cages at $22 \pm 1^{\circ} \mathrm{C}$ and constant humidity, with a 12/12 light/dark cycle, beginning at $7 \mathrm{am}$. The mice were randomly divided into 8 groups with 7 mice in each one: 1/ WT controls (WT), 2/ IL6KO controls (IL6KO), 3/ WT mice hypothyroid (WT-PTU), 4/ IL6KO hypothyroid (IL6KO-PTU), 5/ WT ovariectomized (WT-Ox), 6/ IL6KO ovariectomized (IL6KO-Ox), 7/ WT hypothyroid ovariectomized (WT-PTU-Ox) and 8/ IL6KO hypothyroid ovariectomized mice (IL6KO-PTU-Ox).

Experimental model of menopause was produced by bilateral ovariectomy carried out in $8-9$ weeks old mice under ketamine $(100 \mathrm{mg} / \mathrm{kg})$ and xylazine-HCL $(10 \mathrm{mg} / \mathrm{kg})$ anesthesia. After their abdomen was opened by midline incision both ovaries were resected. After surgery mice were kept for 24 hours in cages heated up to $27^{\circ} \mathrm{C}$ for recovery, with water and chow available ad libitum. Control mice were sham-operated under similar conditions.

Experimental model of hypothyroidism was induced by administration of $0.1 \%$ solution of propylthiouracyl (PTU) in drinking water at the dose of $60 \mu \mathrm{g} / \mathrm{kg}$ daily over 21 days. Control mice were injected vehicle under the same experimental conditions.

Genotyping. Genomic DNA for IL-6 genotyping was isolated from mouse tails using "Genomic mini" kit (A\&A Biotechnology, Gdansk, Poland) according to the enclosed protocol. PCR was performed using Master Mix $(2 \times)$ (Fermentas) and custom made primers (F 5'-CCATCCAGTTGCCTTCTTG-3', R 5'-AAGTGCAT CATCGTTGTTCATAC-3').

After initial denaturation in $94^{\circ} \mathrm{C}$ over 5 minutes, amplification was performed in thirty PCR cycles under following conditions: $94^{\circ} \mathrm{C} 20$ seconds, $52^{\circ} \mathrm{C} 30$ seconds, $72^{\circ} \mathrm{C}$

3 minutes, with final extension in $72^{\circ} \mathrm{C} 10$ minutes, and in $4{ }^{\circ} \mathrm{C}$ at the end of the procedure. Then DNA was separated by electrophoresis on $1 \%$ agarose gel with ethidium bromide.

Blood specimens. At the end of the experiment, the animals were anesthetized with ketamine $(100 \mathrm{mg} / \mathrm{kg})$ and xylazine-HCL (10 $\mathrm{mg} / \mathrm{kg}$ ), their abdomen was opened by midline incision and the blood was taken from the abdominal aorta of each mouse for measurement of serum concentrations of osteoclast-derived tartrateresistant acid phosphatase form 5a (TRACP5b), osteocalcin, OPG, RANKL and creatinine. The blood was collected to polypropylene tubes without anticoagulant and was incubated in room temperature until the clot was formed and then centrifuged $(2500 \times \mathrm{g}, 15$ minutes). The supernatant (serum) was removed and stored at - $70^{\circ} \mathrm{C}$ until a consecutive analysis. The serum levels of TRACP5b and osteocalcin were determined by enzyme-linked immunosorbent assay commercial kits: TRACP5b (MouseTRAP Assay, SBA Sciences, Turku, Finland; sensitivity $0.1 \mathrm{U} / 1$; intra-assay precision $6.5 \%$; inter-assay variation $8 \%$ ) and osteocalcin (Mouse Osteocalcin EIA kit, Biomedical Technologies Inc., Stoughton, USA; sensitivity $1 \mathrm{ng} / \mathrm{ml}$; intra-assay precision $6 \%$; inter-assay variation $8 \%$ ). The serum concentrations of RANKL (sRANKL) and OPG were estimated by enzyme immunoassay commercial kits: RANKL (Quantikine, R\&D Systems, Abingdon, UK; sensitivity 5 $\mathrm{pg} / \mathrm{ml}$; intra-assay precision $2.2 \%$; inter-assay variation $6.5 \%$ ) and OPG (Quantikine, R\&D Systems, Abingdon, UK; sensitivity 4.5 $\mathrm{pg} / \mathrm{ml}$; intra-assay precision $5.5 \%$; inter-assay variation $7.3 \%$ ). Serum creatinine concentration was measured by autoanalyzer using standard laboratory methods.

Thyroid tissues. To verify an animal model of hypothyroidism (immediately after taking a blood) mice were thyreoidectomized. Both thyroid lobes were fixed in Bouin's fluid for 24 hours in temperature of $+4^{\circ} \mathrm{C}$ and embedded in paraffin in a routine procedure. The specimens were cut into $5 \mu \mathrm{m}$ slices and stained by haematoxylin-eosin. The histological preparations were subjected to analysis, using Olympus Bx50 microscope.

Osteodensitometry. Bone mineral density (BMD) was examined in a-p position by the dual X-ray absorptiometry using Lunar DPX densitometer (Lunar Corporation, Madison, WI) with small animal software. BMD measurements were performed by the same experienced operator. The densitometer was calibrated everyday with a standard phantom specimen. The following sites were examined: the total body, tibia, trochanter and vertebrae L2-L4. BMD values were estimated in $\mathrm{mg} / \mathrm{cm}^{2}$.

Ethical issues. All procedures were performed in compliance with the European Communities Council Directive of 24 November 1986 (86/609/EEC) and were approved by the Local Ethics Committee in Bialystok.

Statistical analysis. The statistical significance was estimated by Mann-Whitney U-test. To evaluate relationships between variables Spearman's test was performed using Statistica 9.0 for Windows XP (StatSoft, Tulsa, USA).

\section{Results}

\section{IL-6 genotyping}

Material from wild-type animals yielded DNA fragments with size ca. $1476 \mathrm{bp}$, whereas DNA fragments from IL6KO animals contained also a fragment of neomycin cassette and were size about 2400 bp (Fig. 1).

\section{Bone turnover serum markers}

As it is shown in Fig. 2 and 3, serum concentrations of TRACP $5 \mathrm{~b}$ and osteocalcin were significantly decreased in propylthiouracyl injected sham-operated IL6-deficient mice. Moreover TRACP 5b values were significantly decreased in both wild-type and IL6KO ovariectomized hypothyroid mice as compared to euthyroid groups of ovariectomized animals. Osteocalcin serum concentrations were increased in all groups 


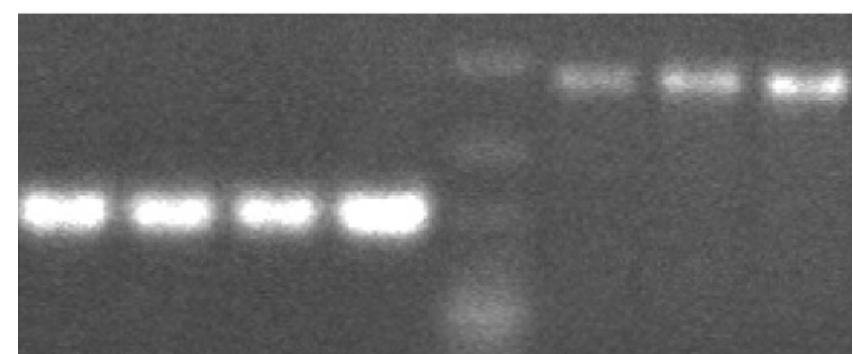

Fig. 1. IL-6 Genotyping of wild-type and IL6KO animals. DNA electrophoresis on agarose gel. Lanes from left side: lanes 1 to $4-$ wild-type $(\mathrm{C} 57 \mathrm{BL} / 6 \mathrm{~J})$ animals, lane 5 - DNA ladder, lanes 6 to 8 - C57BL/6J IL6--/Kopf mice.

of ovariectomized mice. Serum concentrations of TRACP $5 \mathrm{~b}$ (median and interquartile ranges) were respectively: WT (16.4 (13.1-22.0) U/1), IL6KO (12.2 $(10.2-15.5) \mathrm{U} / 1)$, WT-PTU $(9.9$ (7.6-13.2) U/1), IL6KO-PTU (8.0 (6.5-10.8) U/1), WT-Ox (17.2 (15.119.6) U/1), IL6KO-Ox (15.5 (12.0-19.3) U/1), WTPTU-Ox (10.0 (9.1-11.1) U/1) and IL6KO-PTU-Ox (9.2 (7.7-11.6) U/1). Serum levels of osteocalcin (median and interquartile ranges) were respectively: WT (35.8 (31.3-42.5) ng/ml), IL6KO (24.8 (24.8-35.7) $\mathrm{ng} / \mathrm{ml})$, WT-PTU (34.2 (25.7-41.3) ng/ml), IL6KOPTU (15.2 (10.2-19.6) ng/ml), WT-Ox (50.9 (44.658.2) ng/ml), IL6KO-Ox (44.5 (38.7-55.3) ng/ml), WT-PTU-Ox (47.1 (38.7-55.3) ng/ml) and IL6KOPTU-Ox (41.4 (32.1-47.3) ng/ml). In all studied mice TRACP5b and osteocalcin were positively correlated $(\mathrm{R}=0.40 ; \mathrm{p}<0.01)$.

As shown in Fig.4 serum RANKL concentrations were elevated significantly in wild-type ovariectomized mice as compared to controls. Serum RANKL value was significantly lower in IL6KO ovariectomised hypothyroid mice as compared to wild-type animals. Moreover sRANKL values were significantly lower in IL6KO as compared to WT controls and IL6KO PTU injected mice. All sRANKL concentrations (median and interquartile ranges) were respectively: WT (97.9 (79.6-123.8) pg/ml), IL6KO (67.9 (61.4-82.9) pg/ml), WT-PTU (95.5 (88.0-117.4) $\mathrm{pg} / \mathrm{ml})$, IL6KO-PTU (96.3 (86.3-109.75) pg/ml), WTOx (137.8 (123.8-154.7) pg/ml), ), IL6KO-Ox (122.6 (107.6-146.0) pg/ml), WT-PTU-Ox (140.6 (122.6$152.2) \mathrm{pg} / \mathrm{ml}$ ) and IL6KO-PTU-Ox (117.4 (109.1125.4) $\mathrm{pg} / \mathrm{ml}$ ). As shown in Fig. 6 sRANKL values were positively correlated with osteocalcin concentrations in all studied animals $(\mathrm{R}=0.45 ; \mathrm{p}<0.001)$. As illustrated in Fig. 5 osteoprotegerin serum levels were decreased in all IL-6 deficient mice and in a highest degree in sham-operated hypothyroid mice. Serum concentrations of osteoprotegerin (median and interquartile ranges) were respectively: WT (2253 (2002-2414) pg/ml), IL6KO (1716 (1601-1892) pg/ml), WT-PTU (1995 (1857-2072) pg/ml), IL6KOPTU (977 (834-1195) pg/ml), WT-Ox (2028 (1703-
2367) pg/ml), IL6KO-Ox (1695 (1439-1843) pg/ml), WT-PTU-Ox (2118 (1885-2387) pg/ml) and IL6KOPTU-Ox (1869 (1671-2065) pg/ml). We have found positive correlation between osteoprotegerin serum concentrations and osteocalcin values $(\mathrm{R}=0.40$; $\mathrm{p}<0.01)$.

There were no significant differences in creatinine serum concentration in studied groups of mice (data not shown).

\section{Thyroid specimens}

The efficacy of the animal model of hypothyroidism has been confirmed by the histological picture of thyroid glands. The thyroids had a follicular, encapsulated structure in the control and experimental mice. The differences between the central and peripheral follicles in thyroids obtained from both IL6KO and WT control mice were observed. The central follicles had a smaller diameter, the colloid was less dense, and the follicular epithelium was higher, whereas the peripheral follicles were larger filled with intensely stained homogenous colloid, delimited by flat cuboid epithelium. Examination of thyroid sections of IL6KO and WT animals treated with propylthiouracyl pointed to thyroid function blockade with predominance of microfollicular hyperplasia with poor in colloid hyperplastic follicles of irregular shape.

\section{Osteodensitometry}

No significant differences in BMD between groups were found (data not shown).

\section{Discussion}

In the present study serum TRACP $5 b$ concentration, as a marker of bone resorption, was found to be decreased in all groups of hypothyroid mice but osteoprotegerin serum level, as a marker of bone formation, was diminished only in sham-operated PTU injected animals. These data are similar to results of our previous study [11]. Furthermore, in the present study TRACP $5 b$ and osteocalcin measurements have shown that ovariectomy did not influenced significantly bone resorption marker but efficiently stimulated bone formation reflected by osteocalcin. Hypothyroidism is accompanied by deceleration of bone turnover on the contrary to thyrotoxicosis. Triiodotyronine was reported to stimulate osteoblasts activity both directly and indirectly via growth factors and cytokines $[12,13]$. The action of triiodotyronine on osteoclastic bone resorption has been suggested to be mediated predominantly by osteoblast-derived osteotrophic cytokines such as IL-1, IL-6, IL-8 and TNF [12,14]. Data from the studies on osteoblastic bone marrow stromal cells 


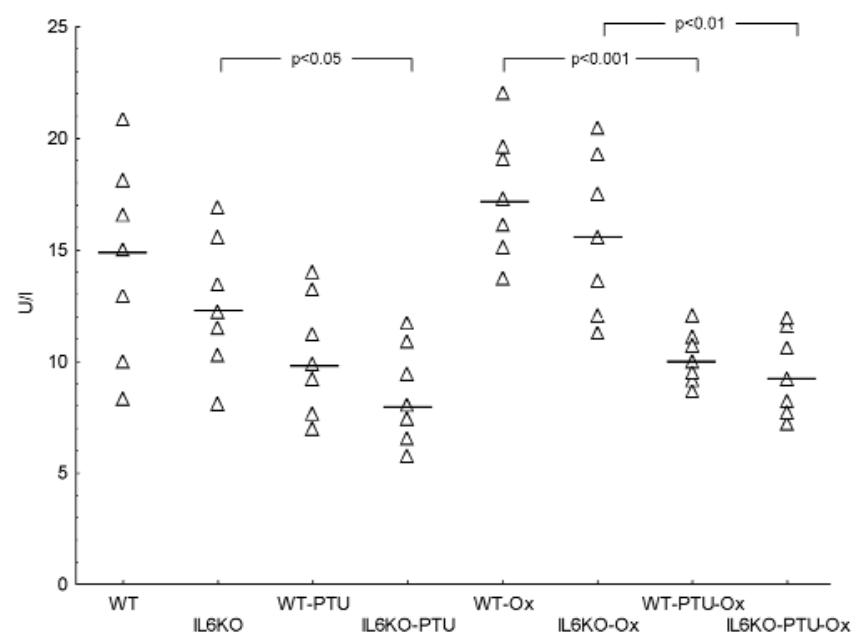

Fig. 2. The individual and median (-) TRACP 5 b serum levels of ovariectomized hypothyroid and euthyroid WT and IL6KO mice as well as control hypothyroid and euthyroid WT and IL6KO mice.

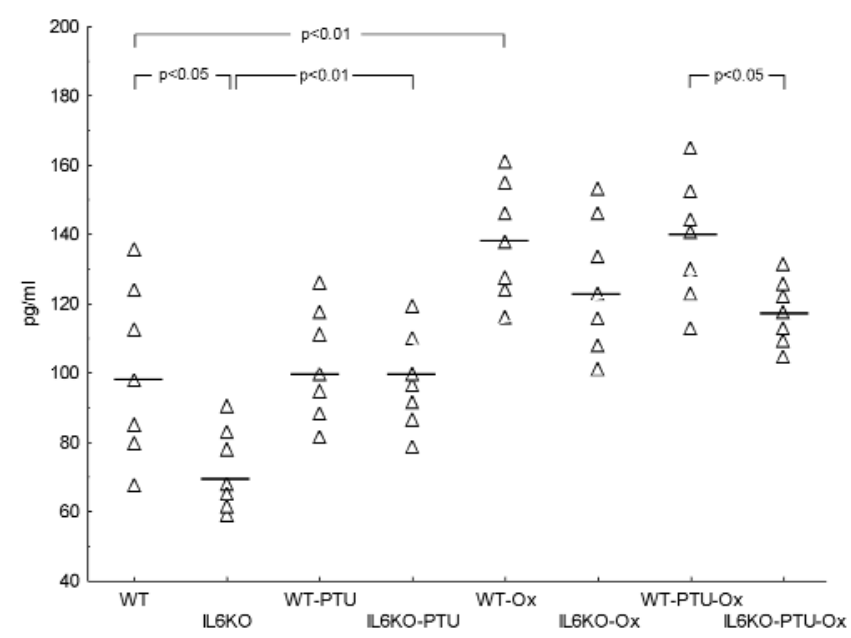

Fig. 4. The individual and median (-) RANKL serum levels of ovariectomized hypothyroid and euthyroid WT and IL6KO mice as well as control hypothyroid and euthyroid WT and IL6KO mice.

and osteoblast cell lines have reported that triiodotyronine stimulates IL- 6 expression and augments IL-1induced stimulation of IL- 6 production $[15,16]$. In the present study ovariectomy had its strongest impact on osteocalcin level in hypothyroid IL-6 deficient mice. Our results suggest that hypothyroidism affects bone formation only in IL-6 deficient animals and that estrogen depletion inhibits this effect. The consequence of ovariectomy was an increase in sRANKL levels in all the studied groups. Our results are consistent with data of Shevde et al. [17] who have shown suppression of RANKL-induced osteoclast differentiation by estrogens via c-Jun repression and results yielded by Shu et al. [18] who documented reversion of stimulatory

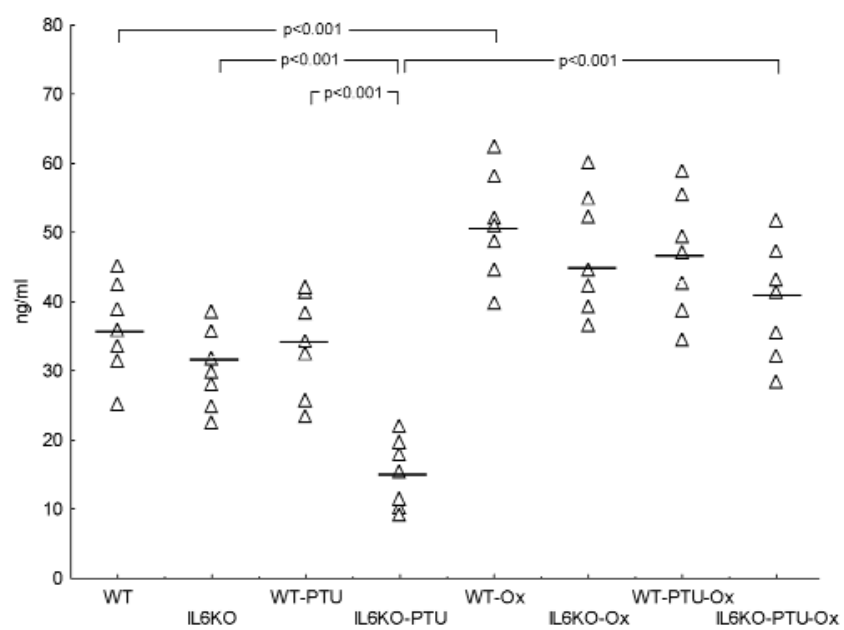

Fig. 3. The individual and median (-) osteocalcin serum levels of ovariectomized hypothyroid and euthyroid WT and IL6KO mice as well as control hypothyroid and euthyroid WT and IL6KO mice.

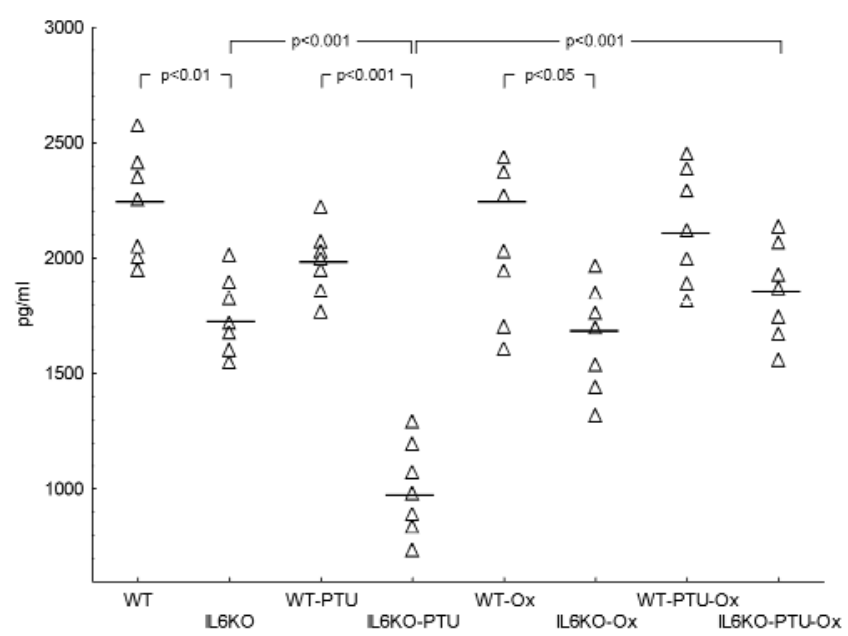

Fig. 5. The individual and median ( - ) osteoprotegerin serum levels of ovariectomized hypothyroid and euthyroid WT and IL6KO mice as well as control hypothyroid and euthyroid WT and IL6KO mice.

effect of lipopolysaccharide on IL-6 and RANKL expression after estrogen administration. Ovariectomy in mice has been shown to increase IL-6 and RANKL expression in bone tissue [19]. Serum RANKL and OPG values were lower in all IL-6 deficient group implying a key regulating role of IL-6 in RANKLRANK/OPG balance. On the other hand, sRANKL elevation in all ovariectomized animals, including hypothyroid IL-6 deficient mice and increase in OPG value in hypothyroid ovariectomized IL-6 deficient animals suggest that estrogens deficit is a strong stimulus for RANKL-RANK/OPG pathway that breaks the inhibitory influence of hypothyroidism even in IL-6 lacking mice. 


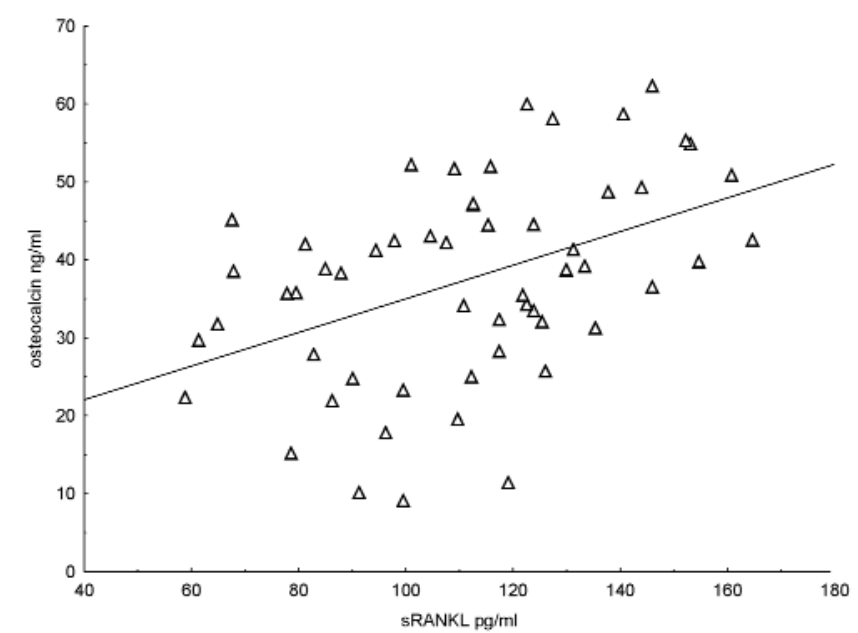

Fig. 6. The correlation between RANKL and in all studied mice $(\mathrm{R}=0.45 ; \mathrm{p}<0.001)$.

The recent discovery of RANK, RANKL and OPGmembers of the TNF and TNF-receptor superfamily enabled to explain the mechanisms of interaction between osteclastic and osteoblastic lineage [20]. RANKL-RANK/ OPG pathway was shown to play a key role in the formation and activation of osteoclasts in conjunction with various cytokines and calciotropic hormones. Experimental studies have proved RANKL expression on osteoblasts and bone marrow stromal cells and its receptor RANK presence in preosteoclasts [21]. The interaction between RANKL and RANK leads to formation and differentiation of osteoclasts by activation of several transcription factors regulating osteoclastogenesis [22-24]. OPG is produced by osteoblasts and is a decoy receptor acting as antagonist (a soluble receptor that competes with RANK for RANKL) $[25,26]$. Up-regulated OPG decreases the interaction of RANKL with RANK leading to reduction of osteoclastic bone resorption. Human bone marrow cells from early postmenopausal women exhibited a greater expression of RANKL compared with estrogen-treated postmenopausal women [27]. 17 $\beta$-estradiol has been shown to increase OPG mRNA in human osteoblastic cell lines [2,24]. Administration of OPG to ovariectomized rats was documented to prevent bone loss [21].

Determination of serum levels of RANKL and OPG in postmenopausal women and their correlation with bone turnover markers and bone mineral density are equivocal $[23,25,26]$. These contradictory findings may relate to differences ethnicity, study design and methodology. OPG levels are increased in osteoporotic women reflecting high bone turnover as compared to nonosteoporotic subjects [27,28]. Association between serum OPG/sRANKL and incidence of bone fractures remains controversial $[29,30]$. We found pos- itive correlations between TRACP and osteocalcin values. Moreover sRANKL and osteoprotegerin serum concentrations were positively correlated with osteocalcin concentrations in all studied animals. These findings may suggest that sRANKL and OPG serum concentration may reflect bone turnover in general, not only bone formation or bone resorption. Separate measurements of sRANKL or OPG seem not to be useful in assessment of bone metabolism.

To sum up, the results of the present study suggest that estrogens deficit is a strong stimulus for RANKLRANK/OPG pathway that breaks an inhibitory influence of hypothyroidism even in IL-6 deficient mice.

Acknowledgements: Authors wish to thank Krystyna Filonczuk MSc for excellent technical assistance. This work was supported by UMB Grant 3-50692 and grant of Polish Ministry of Science N401 103 31/2289.

\section{References}

[1] Mazer NA. Interaction of estrogen therapy and thyroid hormone replacement in postmenopausal women. Thyroid. 2004;14:S27-34.

[2] Manolagas SC, Jilka RL Bone marrow, cytokines and bone remodelling. N Engl J Med. 1995;332:305-311.

[3] Pacifici R. Estrogen, cytokines, and pathogenesis of postmenopausal osteoporosis. J Bone Miner Res. 1996;8:10431051

[4] Roodman GD. Paget's disease and osteoclast biology. Exp J Hematol. 1996;27:1229-1241.

[5] Sims NA, Jenkins BJ, Quinn JM, Nakamura A, Glatt M, Gillespie MT, Ernst M, Martin TJ. Glycoprotein 130 regulates bone turnover and bone size by distinct downstream signaling pathways. J Clin Invest. 2004;113:379-389.

[ 6] Poli V, Balena R, Fattori E, Markatos A, Yamamoto M, Tanaka H, Ciliberto G, Rodan GA, Costantini F. Interleukin-6 deficient mice are protected from bone loss caused by estrogen depletion. EMBO J. 1994;13:1189-1196.

[7] Hayashi M, Rho MC, Enomoto A, Fukami A, Kim YP, Kikuchi Y, Sunazuka T, Hirose T, Komiyama K, Omura S. Suppression of bone resorption by madindoline A, a novel nonpeptide antagonist to gp130. Proc Natl Acad Sci USA. 2002;12:14728-14733

[8] O'Brien CA, Gubrij I, Lin SC, Saylors RL, Manolagas SC. STAT3 activation in stromal osteoblastic cells is required for induction of the receptor activator of NF- B ligand and stimulation of osteoclastogenesis by gp130-utilizing cytokines or interleukin-1 but not 1,25-dihydroxyvitamin D3 or parathyroid hormone. J Biol Chem. 1999;274:19301-19308.

[9] Liu XH, Kirschenbaum A, Yao S, Levine AC. Interactive effect of interleukin-6 and prostaglandin E2 on osteoclastogenesis via the OPG/RANKL/RANK system. Ann N Y Acad Sci. 2006;1068: 225-233.

[10] Mysliwiec J, Zbucki R, Winnicka M, Sawicki B, Nikolajuk A, Kaminski K, Mysliwiec P, Musial W, Bondyra Z, Walecki J, Gorska M. A crucial role of interleukin-6 in the pathogenesis of thyrotoxicosis-related disturbances of bone turnover in mice. Horm Metab Res. 2007;39:1-5.

[11] Mysliwiec J, Zbucki R, Winnicka M, Sawicki B, Nikolajuk A, Kaminski K, Mysliwiec P, Musial W, Bondyra Z, Walecki J, Gorska M. Interleukin-6 is not essential for bone turnover in hypothyroid mice. Folia Histochem Cytobiol. 2007;45:1-6. 
[12] Pereira RC, Jorgetti V, Canalis E. Triiodothyronine induces collagenase-3 and gelatinase B expression in murine osteoblasts. Am J Physiol Endocrinol Metab. 1999;277:E496E504.

[13] Stevens DA, Harvey CB, Scott AJ, O'Shea PJ, Barnard JC, Williams AJ, Brady G, Samarut J, Chassande O, Williams GR. Thyroid Hormone Activates Fibroblast Growth Factor Receptor-1 in Bone. Mol Endocrinol. 2003;17:1751-1766.

[14] Siddiqi A, Monson JP, Wood DF, Besser GM, Burrin JM. Serum cytokines in thyrotoxicosis. J Clin Endocrinol Metab. 1999; 84:435-439.

[15] Siddiqi A, Burrin JM, Wood DF, Monson JP. Tri-iodothyronine regulates the production of interleukin- 6 and interleukin8 in human bone marrow stromal and osteoblast-like cells. $J$ Endocrinol. 1998;157:453-461.

[16] Kim CH, Kim HK, Shong YK. Thyroid hormone stimulates basal and interleukin (IL)-1-induced IL-6 production in human bone marrow stromal cells: a possible mediator of thyroid hormone-induced bone loss. J Endocrinol. 1999;160:97102.

[17] Shevde NK, Bendixen AC, Dienger KM and Pike JW. Estrogens suppress RANK-ligand induced osteoclast differentiation via a stromal cell independent mechanism involving cJun repression. PNAS. 2000;97:7829-7834.

[18] Shu L, Guan SM, Fu SM, Guo T, Cao M and Ding Y. Estrogen modulates cytokine expression in human periodontal ligament cells. J Dent Res. 2008;87:142-147.

[19] Kodama I, Niida S, Sanada M, Yoshiko Y,Tsuda M, Maeda N, Ohama K. Estrogen regulates the production of VEGF for osteoclast formation and activity in op/op mice. J Bone Mineral Res. 2004;19:200-206.

[20] Suda T, Takahashi N, Udagawa N. Modulation of osteoclast differentiation and function by the new members of tumor necrosis factor receptor and ligand families. Endocrine Rev. 1999;20:345-357.

[21] Bolon B, Carter C, Daris M, Morony S, Capparelli C, Hsieh A, Mao M, Kosteniuk P, Dunstan CR, Lacey DL, Sheng JZ. Adenoviral delivery of osteoprotegerin ameliorates bone resorption in a mouse ovariectomy model of osteoporosis. Mol Ther. 2001;3:197-205.

[22] Simonet WS, Lacey DL, Dunstan CR, Kelley M, Chang MS Luthy R, Nguyen HQ, Wooden S, Bennett L, Boone T, Shi- mamoto G, DeRose M, Elliott R, Colombero A, Tan HL, Trail G, Sullivan J, Davy E, Bucay N, Renshaw-Gegg L, Hughes TM, Hill D, Pattison W, Campbell P, Sander S, Van G, Tarpley J, Derby P, Lee R, Boyle WJ. Osteoprotegerin: a novel secreted protein involved in the regulation of bone density. Cell. 1997;89:309-319.

[23] Eghbali-Fatourechi G, Khosla S, Sanyal A, Boyle WJ, Lacey DL, Riggs BL. Role of RANK ligand in mediating increased bone resorption in early postmenopausal women. $J$ Clin Invest. 2003;111:1221-1230.

[24] Jilka RL. Cytokines, bone remodeling, and estrogen deficiency: a 1998 update. Bone. 1998;23:75-81

[25] Han KO, Choi JT, Choi HA, Moon IG, Yim CH, Park WK, Yoon HK, Han IK. The changes in circulating osteoprotegerin after hormone therapy in postmenopausal women and their relationship with oestrogen responsiveness on bone. Clin Endocrinol (Oxf). 2005;62:349-353.

[26] Rogers A, Saleh G, Hannon RA, Greenfield D, Eastell R. Circulatingn estradiol and osteoprotegerin as determinants of bone turnover and bone density in postmenopausal women. $J$ Clin Endocrinol Metab. 2002;87:4470-4475.

[27] Riggs BL, Khosla S, Atkinson EJ, Dunstan CR, Melton 3rd LJ. Evidence that type I osteoporosis results from enhanced responsiveness of bone to estrogen deficiency. Osteoporos Int. 2003;14:728-733.

[28] Jorgensen HL, Kusk P, Madsen B, Fenger M, Lauritzen JB. Serum osteoprotegerin (OPG) and the A163G polymorphism in the OPG promoter region are related to peripheral measures of bone mass and fracture odds ratios. $J$ Bone Miner Metab. 2004;22:132-138.

[29] Browner WS, Lui LY, Cummings SR. Associations of serum osteoprotegerin levels with diabetes, stroke, bone density, fractures, and mortality in elderly women. J Clin Endocrinol Metab. 2001;86:631-637.

[30] Schett G, Kiechl S, Redlich K, Oberhollenzer F, Weger S, Egger G, Mayr A, Jocher J, Xu Q, Pietschmann P, Teitelbaum $\mathrm{S}$, Smolen J, Willeit J. Soluble RANKL and risk of nontraumatic fracture. JAMA. 2004;291:1108-1113.

Submitted: 6 July, 2010 Accepted after reviews: 11 August, 2010 